\title{
Radioactive aerosol particles released from a pneumatic irradiation system in a nuclear research reactor
}

\author{
By Y. Oki ${ }^{1}{ }^{*}$, A. Ozaki ${ }^{2}$, N. Osada ${ }^{3}$, T. Kaneto ${ }^{3}$, Y. Hata ${ }^{2}$, K. Yamasaki ${ }^{1}$ and S. Shibata ${ }^{1}$ \\ ${ }^{1}$ Kyoto University Research Reactor Institute, Kumatori, Osaka 590-0494, Japan \\ 2 Faculty of Engineering, Kyoto University, Yoshida-Honmachi, Sakyo-ku, Kyoto 606-8501, Japan \\ ${ }^{3}$ Graduate School of Engineering, Kyoto University, Kyoto daigaku-Katsura, Nishikyo-ku, Kyoto 615-8530, Japan
}

(Received December 23, 2009; accepted in revised form December 12, 2010)

\author{
Particle size distribution / Radioactive aerosol / \\ Pneumatic tube / Research reactor / \\ Radiation-induced aerosol / $\gamma$-ray irradiation
}

radioactive aerosols in radiation facilities including highintensity accelerators.

\section{Experimental}

\subsection{Collection of airborne radioactivity from a pneumatic tube}

Fig. 1 shows schematic diagram of the pneumatic transport system of the KUR. The irradiation capsule is transported by compressed $\mathrm{CO}_{2}$ gas to the irradiation position in the reactor core. The tube in the reactor is made of an aluminum alloy (No. 5052), and the other part of the tube is made of stainless steel. Four pneumatic tubes are available for sample irradiation in the KUR. In the present work, the Pn-2 pneumatic station was selected for collection of airborne radioactivity because the highest neutron flux was obtained using the Pn-2 among the pneumatic tubes. The nominal fluxes of thermal, epithermal, and fast neutrons of the Pn- 2 are $2.8 \times 10^{13}$, $1.1 \times 10^{12}$ and $6.0 \times 10^{12} \mathrm{n} / \mathrm{cm}^{2} / \mathrm{s}$, respectively. The $\gamma$-ray dose is $1.2 \mathrm{MGy} / \mathrm{h}$ at the irradiation position in the reactor core. The Pn-2 station consists of the inlet of the tube, a PC which controls irradiation time, and a radiation-shielded hot cell. The outlet of the tube is located in the hot cell. After the irradiation the irradiation capsule is ejected from the outlet in the cell, and slows down quickly in a speed reducer like a ball in a roulette wheel. The irradiation capsule is made of polyethylene ( $10 \mathrm{~cm}$ in length and $3 \mathrm{~cm}$ in diameter). The capsule is transported from the Pn-2 station to the reactor core with the compressed $\mathrm{CO}_{2}$ gas and is returned to the cell automatically according to a programmed irradiation time. To avoid damage of irradiation samples and melting of the capsule, $\mathrm{CO}_{2}$ gas is circulated in the pneumatic system to cool the capsule during irradiation as shown in Fig. 1. The temperature of the capsule reaches $c a .70{ }^{\circ} \mathrm{C}$ during $30 \mathrm{~min}$ irradiation [2].

An empty irradiation capsule was transported to the reactor core, and was irradiated for $30 \mathrm{~min}$ under the condition of 5-MW operation. After the irradiation, the $\mathrm{CO}_{2}$ gas released together with the capsule in the cell was sampled with a filter assembly connected to an air sampler at the rate of $50 \mathrm{~L} / \mathrm{min}$. A sampling cone was placed on the outlet of the pneumatic tube to depress diffusion of the released gas, and

*Author for correspondence (E-mail: oki@ rri.kyoto-u.ac.jp). 


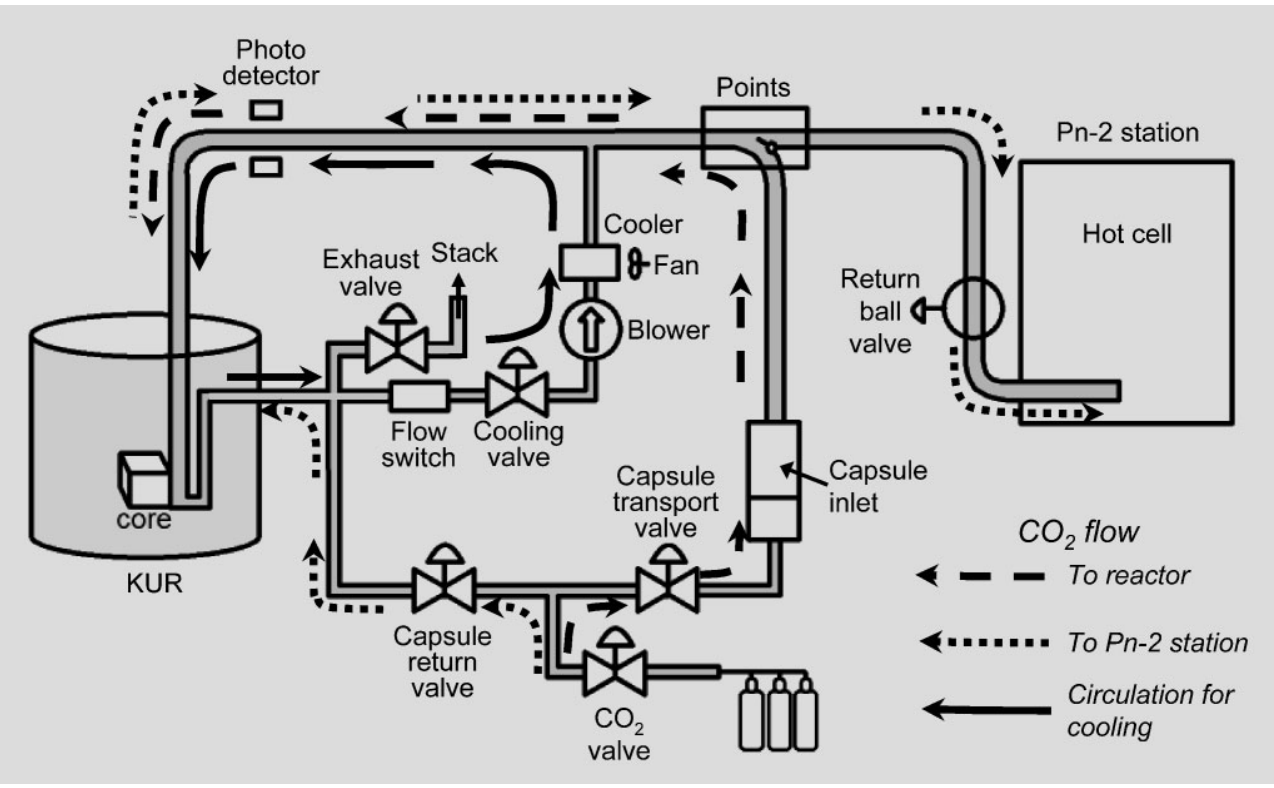

Fig. 1. Schematic diagram of the pneumatic transport system in the KUR. the gas was introduced from the cone to the filter assembly. The ventilation system of the cell was stopped during the sampling to avoid loss of the gas. The sampling was started just before the irradiated polyethylene capsule returned to the hot cell, and was continued for $c a$. $10 \mathrm{~min}$. The temperature of the released gas was almost room temperature. For collection of airborne radioactivity the filter assembly consisting of a particulate filter (Millipore, Type HA, $47 \mathrm{~mm}$ diameter) and two charcoal cartridges (Toyo Roshi Kaisha Ltd., Type CHC-50, 10\% TEDA-impregnated charcoal cartridge) was employed. The aerosol fraction was collected with the particulate filter, and then the gas fraction was absorbed with the charcoal cartridges. Their radioactivity was measured with a Ge semiconductor detector (EG\&G ORTEC, Model GEM-50195, 56\% relative efficiency, $1.95 \mathrm{keV}$ FWHM at $1.33 \mathrm{MeV}$ ) connected to a $4 \mathrm{k}$-pulse height analyzer. The activity of the filters was determined using a ${ }^{152} \mathrm{Eu}$ standard source with the same counting geometry as the filter samples. A pattern of regularly spaced spots was made on a $47 \mathrm{~mm} \phi$ cellulose filter by pipetting a ${ }^{152} \mathrm{Eu}$ standard solution using a $\mu \mathrm{L}$ piston-stroke precision pipette. The filter was used as the activity standard filter.

\subsection{Particle size measurement of the aerosol}

Particle size distributions of released aerosol particles were measured with a low pressure cascade impactor (Tokyo Dylec Co., Model LP-2015J). The impactor consists of 14 collection stages and a back up filter. The impactor can classify the particles in air into 15 size ranges: $<0.06,0.06-$ $0.12,0.12-0.20,0.20-0.31,0.31-0.42,0.42-0.64,0.64-$ $0.99,0.99-1.4,1.4-1.9,1.9-2.9,2.9-4.6,4.6-0.8,6.8-9.7$, 9.7-15 and $>15 \mu \mathrm{m}$ at the air sampling rate of $21.4 \mathrm{~L} / \mathrm{min}$ at room temperature. In each collection stage, aerosol particles were collected by impaction on a silicone greasecoated thin stainless steel collection plate of $47 \mathrm{~mm}$ in diameter. A Teflon binder filter (Pallflex Products Corp., Type T60A20, $47 \mathrm{~mm}$ in diameter) was used for the backup filter. According to a calibration experiment performed using a radon progeny aerosol in the Kyoto University Critical
Assembly (KUCA) building [3], the silicone grease-coated plate was selected as the best collection substrate, and the distance between the impactor nozzles and the collection plate was optimized using spacer plates.

The $\mathrm{CO}_{2}$ gas released from the pneumatic tube was sampled from the hot cell with the impactor at the rate of $21.4 \mathrm{~L} / \mathrm{min}$ for $10 \mathrm{~min}$. After the sampling, radioactivity of the collection plate and the backup filter were measured with the same Ge detector system as mentioned above.

\subsection{Particle creation by $\gamma$-ray irradiation to $\mathrm{CO}_{2}$ gas}

Radiation-induced aerosols are often observed in highly irradiated air of accelerator rooms or tunnels $[4,5]$. To examine the possibility of aerosol formation in $\mathrm{CO}_{2}$ gas by radiation, the same $\mathrm{CO}_{2}$ gas as that used in the pneumatic system was irradiated with $\gamma$-rays of ${ }^{60} \mathrm{Co}$ in the $\gamma$-ray irradiation facility in the KURRI. The irradiation was performed at a position of $2.42 \mathrm{kGy} / \mathrm{h}$ at room temperature using a $414-\mathrm{TBq}{ }^{60} \mathrm{Co}$ source. The $\mathrm{CO}_{2}$ gas was introduced at the rate of $2 \mathrm{~L} / \mathrm{min}$ to a 1.7-L irradiation chamber placed in the irradiation room of the facility, and the irradiated $\mathrm{CO}_{2}$ gas was returned to an experiment room outside of the irradiation room. The particle number concentration in the irradiated $\mathrm{CO}_{2}$ was measured with a condensation particle counter (CPC) (TSI Inc., Model 3025A-S).

\section{Results and discussion}

\subsection{Airborne radionuclides released from the pneumatic tube}

The average volume of the released $\mathrm{CO}_{2}$ gas from the pneumatic tube was determined to be approximately $150 \mathrm{~L}$ in a measurement separately carried out when the reactor was not operated. Fig. 2 shows $\gamma$-ray spectra of the aerosol fraction collected with the particulate filter and the gas fraction collected with the charcoal cartridge. The activity measurement was started approximately $3 \mathrm{~min}$ after the end of the sampling, and was measured for $1000 \mathrm{~s}$. Fission products 
Table 1. Concentration of radioactive nuclides released from the pneumatic tube ${ }^{a}$.

\begin{tabular}{|c|c|c|c|c|c|}
\hline \multirow[t]{2}{*}{ Nuclide } & \multirow[t]{2}{*}{ Half life } & \multirow{2}{*}{$\begin{array}{c}\text { Aerosol } \\
\left(\mathrm{Bq} / \mathrm{cm}^{3}\right)\end{array}$} & \multirow{2}{*}{$\begin{array}{c}\text { Gas } \\
\left(\mathrm{Bq} / \mathrm{cm}^{3}\right)\end{array}$} & \multicolumn{2}{|c|}{ Limit of air concentration $^{b}$} \\
\hline & & & & $\begin{array}{l}\text { in controlled } \\
\text { area }\left(\mathrm{Bq} / \mathrm{cm}^{3}\right)\end{array}$ & $\begin{array}{c}\text { at stack } \\
\left(\mathrm{Bq} / \mathrm{cm}^{3}\right)\end{array}$ \\
\hline${ }^{24} \mathrm{Na}$ & $14.96 \mathrm{~h}$ & $6.7 \mathrm{E}-04$ & N.D. ${ }^{c}$ & 4.E-02 & 4.E-04 \\
\hline${ }^{38} \mathrm{Cl}$ & $37.24 \mathrm{~m}$ & N.D. & $1.2 \mathrm{E}-02$ & 3.E-01 & 3.E-03 \\
\hline${ }^{56} \mathrm{Mn}$ & $2.579 \mathrm{~h}$ & $3.3 \mathrm{E}-04$ & N.D. & 1.E-01 & 1.E-03 \\
\hline${ }^{82} \mathrm{Br}$ & $1.471 \mathrm{~d}$ & N.D. & $1.6 \mathrm{E}-04$ & 2.E-02 & 2.E-04 \\
\hline${ }^{84} \mathrm{Br}$ & $31.8 \mathrm{~m}$ & N.D. & $3.6 \mathrm{E}-03$ & 3.E-01 & 3.E-03 \\
\hline${ }^{88} \mathrm{Rb}$ & $17.8 \mathrm{~m}$ & $5.1 \mathrm{E}-04$ & N.D. & 7.E-01 & 7.E-03 \\
\hline${ }^{89} \mathrm{Rb}$ & $15.2 \mathrm{~m}$ & $8.5 \mathrm{E}-03$ & N.D. & 8.E-01 & 8.E-03 \\
\hline${ }^{90} \mathrm{Rb}$ & $2.60 \mathrm{~m}$ & $1.6 \mathrm{E}-02$ & N.D. & 3.E+00 & 3.E-02 \\
\hline${ }^{132} \mathrm{I}$ & $2.30 \mathrm{~h}$ & N.D. & $1.7 \mathrm{E}-04$ & 7.E-02 & 4.E-04 \\
\hline${ }^{133} \mathrm{I}$ & $20.8 \mathrm{~h}$ & N.D. & $1.6 \mathrm{E}-04$ & 5.E-03 & 3.E-05 \\
\hline${ }^{134} \mathrm{I}$ & $52.6 \mathrm{~m}$ & N.D. & $2.1 \mathrm{E}-03$ & 1.E-01 & 8.E-04 \\
\hline${ }^{135} \mathrm{I}$ & $6.57 \mathrm{~h}$ & N.D. & $6.7 \mathrm{E}-04$ & 2.E-02 & 1.E-04 \\
\hline${ }^{135 m} \mathrm{Xe}$ & $15.29 \mathrm{~m}$ & N.D. & $2.0 \mathrm{E}-03$ & 4.E-01 & 2.E-03 \\
\hline${ }^{135} \mathrm{Xe}$ & $9.14 \mathrm{~h}$ & N.D. & $5.3 \mathrm{E}-04$ & 6.E-01 & 3.E-03 \\
\hline${ }^{138} \mathrm{Xe}$ & $14.1 \mathrm{~m}$ & N.D. & 7.3E-04 & 1.E-01 & 6.E-04 \\
\hline${ }^{138} \mathrm{Cs}$ & $32.2 \mathrm{~m}$ & $5.9 \mathrm{E}-03$ & $-{ }^{d}$ & 5.E-01 & 5.E-03 \\
\hline${ }^{139} \mathrm{Cs}$ & $9.27 \mathrm{~m}$ & 8.0E-04 & N.D. & 1. $\mathrm{E}+00$ & 1.E-02 \\
\hline${ }^{139} \mathrm{Ba}$ & $1.382 \mathrm{~h}$ & 7.3E-04 & N.D. & 4.E-01 & 3.E-03 \\
\hline
\end{tabular}

a: Activity concentration at the end of irradiation;

b: Derived air concentration given in [4];

c: Not detected;

$\mathrm{d}$ : The activity of ${ }^{138} \mathrm{Cs}$ was detected in the gas fraction due to decay of ${ }^{138} \mathrm{Xe}$.

were detected in addition to the radionuclides, such as ${ }^{24} \mathrm{Na}$, which were produced through neutron-induced reactions other than nuclear fission. Activity concentrations of air-
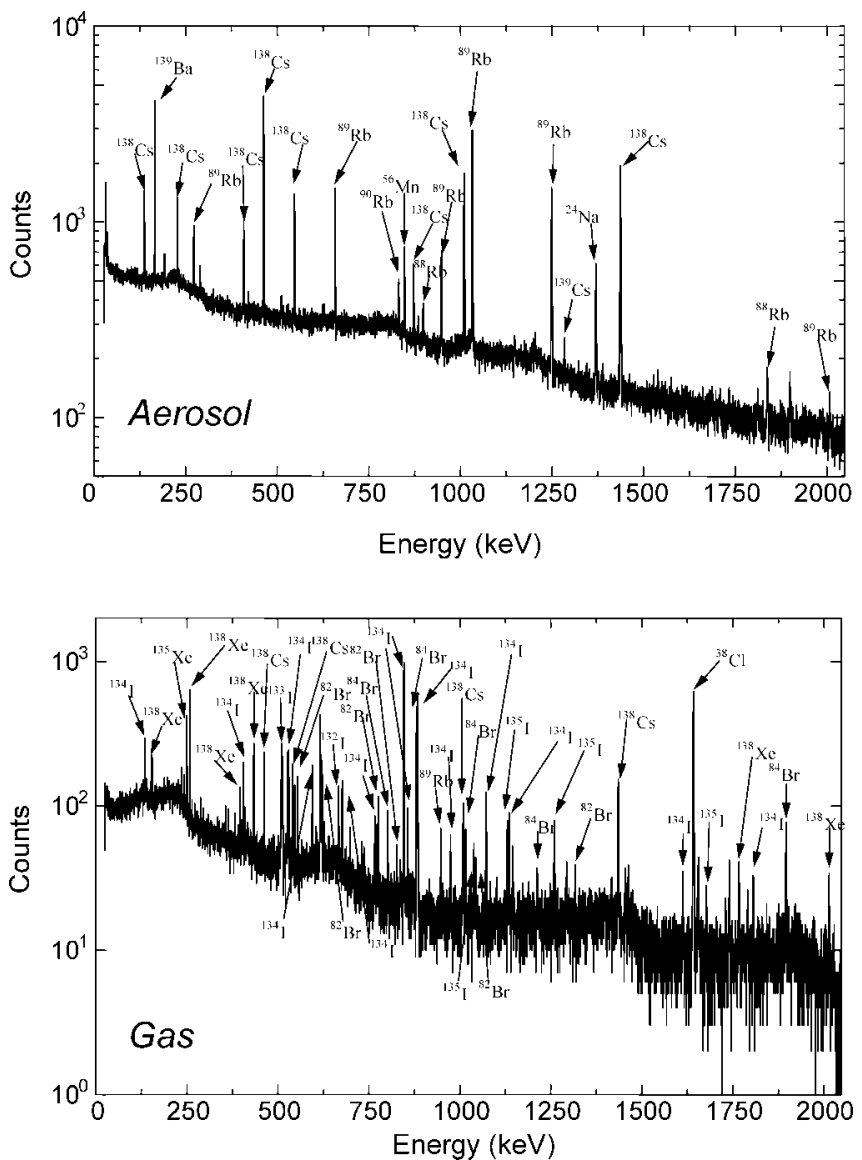

Fig. 2. Gamma-ray spectra of collected radioactive aerosol and gas released from the pneumatic tube. borne radionuclides detected in the released gas were calculated by dividing the collected activity at the end of irradiation by both of the average volume of the released $\mathrm{CO}_{2}$ gas, $150 \mathrm{~L}$ and their collection efficiency. The obtained concentrations are listed in Table 1 . The collection efficiency for the aerosol fraction was estimated to exceed $99 \%$, while that for the gas fraction was dependent on nuclides. The efficiency for ${ }^{38} \mathrm{Cl}$ was $90 \%$, and both bromine and iodine isotopes reached $100 \%$. On the other hand, the efficiency for xenon isotopes was ranged from 52 to $84 \%$. All nuclides except for ${ }^{24} \mathrm{Na},{ }^{38} \mathrm{Cl}$, and ${ }^{56} \mathrm{Mn}$ were identified as fission products. Only ${ }^{138} \mathrm{Cs}$ was detected in both of the aerosol fraction and the gas fraction. Because ${ }^{138} \mathrm{Xe}$, the parent of ${ }^{138} \mathrm{Cs}$, was collected in the gas fraction, ${ }^{138} \mathrm{Cs}$ observed in the gas fraction is considered to be due to the decay of ${ }^{138} \mathrm{Xe}$. A part of ${ }^{138} \mathrm{Cs}$ in the aerosol fraction is thought to be formed by the ${ }^{138} \mathrm{Xe}$ decay which took place in the $\mathrm{CO}_{2}$ gas during irradiation.

The concentration limits [6] of radionuclides in air of radioisotope experiment rooms of the radiation controlled area and at a stack of facilities were also shown in Table 1. From the viewpoint of the radiation protection, the released $\mathrm{CO}_{2}$ gas was safe because the activity concentrations in air were lower than the limit in the controlled area, and because the concentration in the stack of the facility did not exceed the limit at the stack, taking into account of dilution by a large volume of the exhaust air from the facility.

The ${ }^{24} \mathrm{Na}$ and ${ }^{38} \mathrm{Cl}$ are produced through $(n, \gamma)$ reactions of $\mathrm{NaCl}$ contaminant which exists on the outer surface of the irradiation capsule and the inner surface of the pneumatic tube. In addition to the $(n, \gamma)$ reaction, ${ }^{24} \mathrm{Na}$ is also formed through the $(n, \alpha)$ reaction of ${ }^{27} \mathrm{Al}$ used in the part of the reactor core of the pneumatic tube. Since manganese is contained as a minor component or an impurity in the alu- 


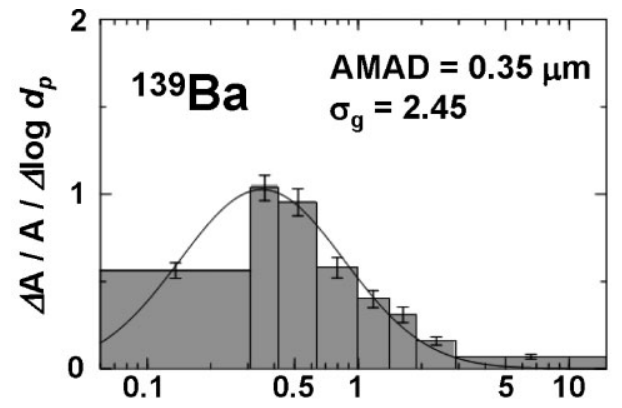

Aerodynamic Diameter $\left(d_{p}\right) / \mu \mathrm{m}$

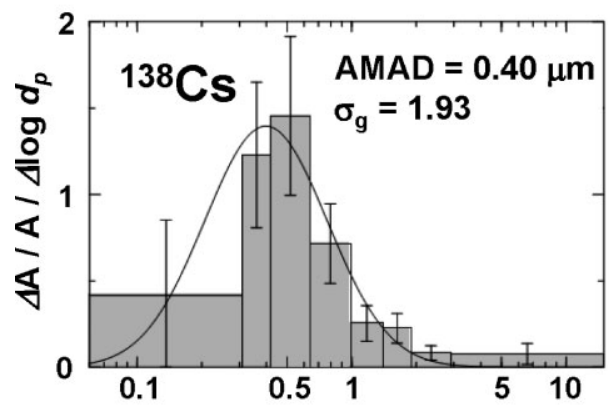

Aerodynamic Diameter $\left(d_{p}\right) / \mu \mathrm{m}$
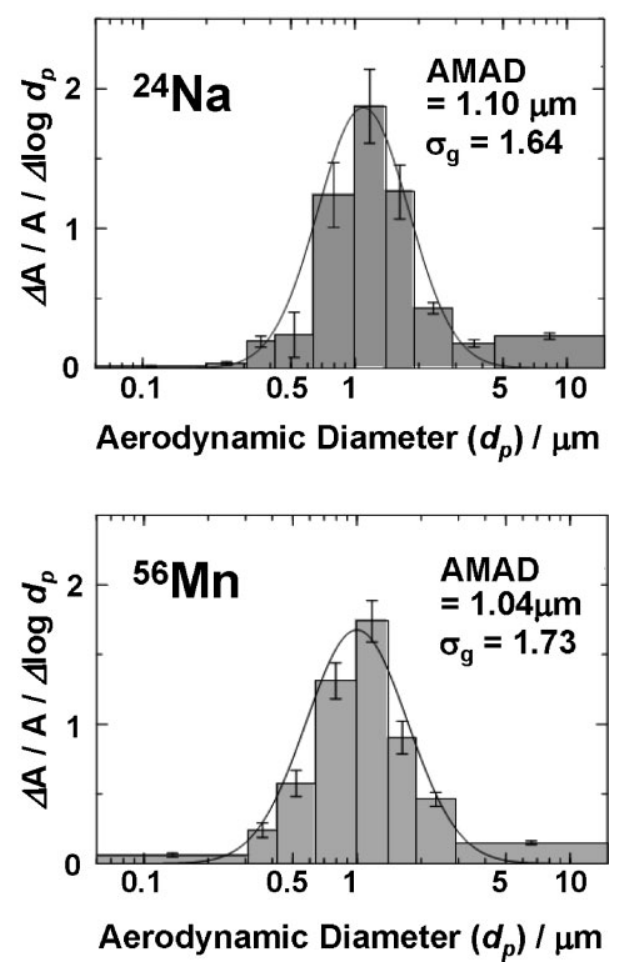

Fig. 3. Particle size distribution of the radioactive aerosols released from the pneumatic tube. minum alloy, the ${ }^{56} \mathrm{Mn}$ is formed through ${ }^{56} \mathrm{Mn}(n, \gamma){ }^{56} \mathrm{Mn}$ reaction.

As the inner surface of the pneumatic tube is never contaminated with nuclear fuel, the origin of the fission products is considered to be uranium impurity contained in the aluminum alloy. A similar detection of fission products was previously evaluated in the primary cooling water system of the KUR due to an impurity of uranium contained in clad materials [7].

\subsection{Size distribution of the aerosol particles}

A mixture of the released $\mathrm{CO}_{2}$ gas and air was sucked by the impactor in the gas sampling in the cell. Because the size ranges in the impactor measurement described above is calibrated in air, the size ranges were corrected for $\mathrm{CO}_{2}$. The $50 \%$ cutoff diameter in $\mathrm{CO}_{2}$ was calculated as follows $[8,9]$ :

$$
\begin{aligned}
& D_{\mathrm{p}}=\sqrt{\frac{18 \mu D \varphi_{50}}{C V_{C} \rho}} \\
& \lambda=\frac{82.057 \mu}{0.499 P} \times \sqrt{\frac{\pi T}{8 M R}} \\
& C=1+\frac{\lambda}{D_{\mathrm{p}}}\left\{2.514+0.8 \exp \left(\frac{-0.55 D_{\mathrm{p}}}{\lambda}\right)\right\}
\end{aligned}
$$

where $D_{\mathrm{p}}$ is the $50 \%$ cutoff diameter $(\mathrm{cm}), C$ is the Cunningham correction for slip, $\mu$ is viscosity of gas $(/(\mathrm{cm} \mathrm{s}))$, $\rho$ is density of aerosol $\left(\mathrm{g} / \mathrm{cm}^{3}\right), V_{\mathrm{c}}$ is velocity of gas at the impactor nozzle $(\mathrm{cm} / \mathrm{s}), D$ is diameter of the nozzle, $\varphi_{50}$ is the non-dimensional inertial parameter for the $50 \%$ cutoff $(0.144), \lambda$ is mean free path of gas $(\mathrm{cm}), P$ is gas pressure at the impaction stage (atm), $T$ is temperature of gas $(\mathrm{K}), M$ is molecular weight of gas $(\mathrm{g} / \mathrm{mol})$, and $R$ is gas constant $8.31 \times 10^{-7} \mathrm{erg} /(\mathrm{mol} \mathrm{K})$.

The calculated difference of the cutoff diameters between air and $\mathrm{CO}_{2}$ was at most approximately $10 \%$. The size distri- bution patterns described below is expressed using the cutoff diameter of air without correction because the mixing ratio of $\mathrm{CO}_{2}$ gas and air cannot be exactly measured when the $\mathrm{CO}_{2}$ gas is released in the hot cell.

The particle size distributions for only 4 nuclides, ${ }^{138} \mathrm{Cs}$ and ${ }^{139} \mathrm{Ba}$ for fission products, and ${ }^{24} \mathrm{Na}$ and ${ }^{56} \mathrm{Mn}$ for other nuclides, were obtained because of their low activity and short half lives. Fig. 3 shows their particle size distributions as a function of aerodynamic diameter of the aerosols. The distributions were normalized by total activity of all size ranges. The error bars were derived from counting statistics. Except for ${ }^{24} \mathrm{Na}$, both foot regions of the peak in the size distributions were expressed as single size ranges by summing activities of collection stages of the foot region because of the low activity. The distribution showed log-normal patterns similar to the accelerator aerosols $[4,5,10]$. The fitted curves to log-normal distribution functions are also shown in Fig. 3.

All of the particle size showed log-normal distributions with a single peak; however, the size distribution was classified into two groups. The activity median aerodynamic diameter, AMAD, $\left(d_{\mathrm{g}}\right)$ and geometric standard deviation $\left(\sigma_{\mathrm{g}}\right)$ of the size distributions were obtained by the fitting to log-normal functions. The $d_{\mathrm{g}}$ was found to be $c a$. $0.4 \mu \mathrm{m}$ for ${ }^{138} \mathrm{Cs}$ and ${ }^{139} \mathrm{Ba}$ and $1 \mu \mathrm{m}$ for ${ }^{24} \mathrm{Na}$ and ${ }^{56} \mathrm{Mn}$. The $\sigma_{\mathrm{g}}$ for ${ }^{138} \mathrm{Cs}$ and ${ }^{139} \mathrm{Ba}$ was obviously larger than that of ${ }^{24} \mathrm{Na}$ and ${ }^{56} \mathrm{Mn}$. It is suggested that there were two different origins of radioactive aerosols. Since the transportation of the capsule causes strong friction between the polyethylene capsule and the inner surface of the pneumatic tube, the surfaces of the aluminum part of the pneumatic tube and the polyethylene capsule are rubbed to produce aluminum and polyethylene dust. It is suggested that particles with the AMAD of $c a$. $1 \mu \mathrm{m}$ is formed by ablation of the activated aluminum during transportation of the capsule.

On the other hand, the size distribution with the AMAD of $c a$. $0.4 \mu \mathrm{m}$ was thought to have a different origin. It 
is often observed that aerosols are produced in radiationinduced physico-chemical processes in air in high-dose radiation fields such as high-energy proton accelerators [4,5] and electron linear accelerators [10]. Contrary to the activation of the dust particles mentioned above, the radioactive aerosol particles are formed by attachment of airborne radioactive atoms in air to the radiation-induced aerosol particles. The airborne radioactive atoms are formed in air of the accelerator room or by recoil from accelerator hardware. In the pneumatic system the capsule and $\mathrm{CO}_{2}$ gas are exposed to high dose of radiation in the reactor core similarly to high-dose areas of the accelerator rooms. Although the atmosphere in the pneumatic tube, $\mathrm{CO}_{2}$, is different from that in accelerator rooms, a similar nucleation of aerosols induced by radiation may take place even in the $\mathrm{CO}_{2}$ gas.

In order to examine the possibility of aerosol formation in $\mathrm{CO}_{2}$, the $\gamma$-ray irradiation experiment was carried out as mentioned above. The dose given to the $\mathrm{CO}_{2}$ gas was 40 Gy. Although this $\gamma$-dose was much lower than that of the pneumatic tube, $c a$. $600 \mathrm{kGy} / 30 \mathrm{~min}$, the formation of the radiation-induced particles was observed. The number of the radiation-induced particles exceeded the upper limit of detection of the $\mathrm{CPC}, 1 \times 10^{5}$ particles $/ \mathrm{cm}^{3}$. This result suggests that the aerosols of $c a$. $0.4 \mu \mathrm{m}$ were produced by radiation-induced reactions that took place in $\mathrm{CO}_{2}$. Similar to the accelerator aerosols, the aerosol particles are considered to grow from initial nano-size to sub-micron size. The growth of the particles may be much enhanced by high dose radiation and high temperature in the irradiation position in the reactor core. The recoiled fission product atoms from trace uranium in aluminum are considered to form radioactive aerosols by attaching to the ambient radiation-induced aerosols similarly to the case of the high energy proton accelerator.

\section{Conclusions}

The radionuclides released from the pneumatic tube were identified as ${ }^{24} \mathrm{Na},{ }^{38} \mathrm{Cl},{ }^{56} \mathrm{Mn}$ and fission products such as ${ }^{88} \mathrm{Rb},{ }^{138} \mathrm{Cs}$ and ${ }^{139} \mathrm{Ba}$. They are considered to be formed through nuclear reactions of $\mathrm{NaCl}$ existing on the inner surface of the pneumatic tube or aluminum used in the tube in the reactor core or its minor components including impurity such as manganese and uranium. The particle size of the radioactive aerosols showed log-normal distributions with a single peak; however, the AMAD was classified into two groups, $c a$. $1 \mu \mathrm{m}$ and $c a$. $0.4 \mu \mathrm{m}$. They have different origins. It is suggested that the $1-\mu \mathrm{m}$ particles are formed by the activation of aluminum dust particles produced by ablation of the inner surface of the pneumatic tube during transportation of the capsules. In contrast, the $0.4 \mu \mathrm{m}$ particles might be formed by the attachment process of fission products emitted by recoil to radiation-induced aerosols.

\section{References}

1. Tsujimoto, H.: Reconstruction of Pneumatic Irradiation Facility in Kyoto University Reactor, Tech. Rep. Res. Reactor Inst. Kyoto Univ., KURRI-TR-202 (1980) [in Japanese].

2. Okada, M., Kitaoka, Y., Takada, J., Kobayashi, M., Tsujimoto, H., Kozuka, T., Kodaka, H., Kanda, K.: Irradiation Temperature in a Polyethylene Capsule and a Capacity of a Cooling System of the Pneumatic Irradiation Facility in the KUR, Tech. Rep. Res. Reactor Inst. Kyoto Univ., KURRI-TR-431 (2000) [in Japanese].

3. Yamasaki, K., Oki, Y., Yamada, Y., Tokonami, S., Iida, T.: Optimization of measuring methods on size distribution of naturally occurring radioactive aerosols. Int. Congr. Ser. 1276, 297 (2005).

4. Kondo, K., Muramatsu, H., Kanda, Y., Takahara, S.: Int. J. Appl. Radiat. Isot. 35, 939 (1984).

5. Muramatsu, H., Kondo, K., Kanda, Y.: Appl. Radiat. Isot. 39, 413 (1988).

6. The Japanese Laws Concerning the Prevention from Radiation Hazards Due to Radioisotopes and Others (revised in 2001).

7. Matsushita, R., Koyama, M.: The origin of fission products in primary cooling water: evaluation of contribution of uranium contained in clad materials as an impurity. Annu. Rep. Res. Reactor Inst. Kyoto Univ. 11, 169-176 (1978).

8. Ranz, W. E., Wong, J. B.: Impaction of dust and smoke particles on surface and body collections. Ind. Eng. Chem. 44, 1371 (1952).

9. Stern, S. C., Zeller, H. W., Schekman, A. I.: Collection efficiency of jet impactors at reduced pressures. Ind. Eng. Chem. Fundamen. 1, 273 (1962).

10. Yokoyama, S., Yamasaki, K., Oki, Y., Osada, N.: Time variation of particle size distribution of aerosols generated at accelerator facilities. Jpn. J. Health Phys. 43, 333 (2008) [in Japanese]. 